\title{
GENÉTICA Y BIOÉTICA EN AMÉRICA LATINA
}

\section{Claude Vergès*}

Resumen: Las implicaciones bioéticas de la genética en América Latina: se analizan las relaciones entre el poder científico y los derechos humanos en las condiciones particulares de este continente. En particular, el mito de la salud perfecta que rodea a la genética permite abusos de los derechos de las personas en sociedades poco democráticas. El análisis de las recomendaciones de la Organización Mundial de la Salud para la consejería genética y las pruebas genéticas muestra que la bioética debe estar vigilante en su aplicación.

Palabras clave: Bioética, genética, América Latina

\section{GENETICS AND BIOETHICS IN LATIN AMERICA}

\begin{abstract}
The relations between genetics and bioethics in Latin America are analyzed through the relations between scientific power and human rights in the particular conditions of this continent. Particularly, the myth of genetics'power to reach perfect health is allowing abuses of human rights in poor democratic societies. The analysis of the recommendations of the World Health Organization for genetic counseling and genetic probes shows that bioethics must be vigilant in its applications.
\end{abstract}

Key words: Bioethics, genetics, Latin America

\section{GENÉTICA E BIOÉTICA NA AMÉRICA LATINA}

Resumo: As implicações bioéticas da genética na América Latina: são analisadas as relações entre o poder científico e os direitos humanos nas condições particulares deste continente. Em particular, o mito da saúde perfeita que rodeia a genética permite abuso dos direitos das pessoas em sociedades pouco democráticas. A análise das recomendações da Organização Mundial da Saúde para o Conselho Genético e as provas genéticas mostra que a bioética deve estar vigilante na sua aplicação.

Palavras-chave: Bioética, genética, América Latina

* Centro de Estudios de Bioética. Facultad de Medicina. Universidad de Panamá

Correspondencia: vergeslopez@cwpanama.net 


\section{Introducción}

Para hablar de las implicaciones bioéticas de la genética en América Latina, analizaremos las relaciones entre el poder del científico y los derechos humanos en las condiciones particulares de este continente, abordaremos luego el mito del poder de la genética para lograr la salud perfecta para, finalmente, seguir con los campos propios de la genética.

\section{El poder científico y los derechos humanos}

No se puede hablar de las implicaciones bioéticas para la genética sin establecer las relaciones entre el poder científico y los derechos de las personas. La medicina, que quiere ser una disciplina científica, ha integrado los principios científicos del universalismo no discriminatorio de las leyes basadas en evidencias (demostradas por la investigación epidemiológica o técnica y de objetividad lograda a través de la supuesta neutralidad de los sentimientos) con los sujetos de la relación clínica.

Contra esta posición ampliamente aceptada en Occidente, la Escuela de Frankfurt recomienda "pensar la técnica", es decir, acompañar activamente a la invención tecnocientífica con la filosofía, la antropología humanista y la sociología para un proyecto más justo y equitativo(1). A esta posición se suma el principio de precaución (Kant, Comte, Jonas), es decir, la elección de la alternativa que maximiza la satisfacción asociada al resultado de la peor de las hipótesis, siguiendo la dinámica de las prioridades y la clarificación permanente de las decisiones tomando en cuenta el peso de la ambigüedad de la información científica(2).

Sin embargo, la medicina sigue manejando el conocimiento específico necesario para la prevención, curación y rehabilitación de las enfermedades con un sesgo cientificista al margen de las humanidades. Además, la medicina se constituyó en un cuerpo de poder que pretende normar todos los actos humanos relacionados con la salud y la sobrevivencia de la especie humana(3). La genética tiene un rol fundamental e irremplazable en la eliminación de enfermedades incompatibles con la vida (síndrome cromosómico) o que afectan severamente a la calidad de la vida humana (cáncer, fibrosis quística, enfermedades del metabolismo), sin contar la posible respuesta a los anhelos humanos de vida eterna y de reproducción de sí mismo. Estas razones pueden explicar la fascinación y el poder que ejerce la genética sobre los individuos y sobre las sociedades, y la pretensión de utilizarla para normar aspectos importantes de la vida humana.

Las investigaciones sin exclusiones a priori han permitido los avances científicos de la medicina y la desaparición de ciertas enfermedades (viruela) o el control de las mismas (sarampión). La genética es una ciencia relativamente nueva, y sus aplicaciones son más difundidas en el campo de la agricultura y ganadería (con los organismos genéticamente modificados) que en la medicina. A esta última, la genética ha aportado una mejor comprensión de las enfermedades hereditarias y respuestas a los problemas de enfermedades graves y transplantes (con la clonación terapéutica). Por estas razones debemos reconocer la necesidad de la investigación científica, y los límites a su progreso serían contraproducentes. Sin embargo, los errores y abusos cometidos por desconocimiento de las relaciones sociales y de los derechos humanos han sensibilizado a la sociedad actual que intenta fijar límites externos a la ciencia y, particularmente, a la genética, ya que es necesario definir qué es investigación y qué es manipulación. A su vez, y particularmente en América Latina, las religiones, apoyándose en su poder moral, han procurado imponer sus creencias y sus normas con posiciones integristas y excluyentes, desconociendo las 
diferentes situaciones sociales y los derechos de los no creyentes (por ejemplo, las campañas contra toda forma de clonación).

En contraparte, la democratización continua de las relaciones sociales, así como la influencia del modelo liberal, postulan al individuo como valor máximo del modelo de las sociedades modernas. Estos valores están simbolizados en el principio bioético de autonomía de Beauchamp y Childress(4) que se inscribe en el postulado de libertad de los derechos humanos de primera generación (Derechos Políticos, ONU, 1948) y que, en nuestra sociedad, puede ser reemplazado por el principio de integridad del ser humano de Pellegrino. Por otra parte, el avance de los derechos sexuales y reproductivos de las mujeres, reconocidos por las Naciones Unidas en las Conferencias del Cairo, 1984, y de Beijing, 1995, cuestionan el poder médico de utilizar partes o todo el cuerpo de las mujeres sin su pleno consentimiento. Mientras tanto los organismos de la Naciones Unidas, así como los comités de bioética nacionales o supranacionales (Europa), han elaborado recomendaciones y normas para la investigación genética y, particularmente, para su aplicación ${ }^{1}$. El diálogo y la argumentación, definidos como “ética de la discusión” por Habermas y Appel, son necesarios en el ámbito académico y en el público para la elaboración de leyes que expresen el consenso de las mayorías y, a la vez, permitan la resolución de los casos individuales(5).

World Health Organization. Proposed International Guidelines on Ethical Issues in Medical Genetics and Genetic Services. Report of a WHO meeting on ethical issues in medical genetics. 1997; The United Nations Treaty on Human Cloning. [Sitio en Internet] Disponible en http:// genetics-and-society.org/policies/international/ unitednations; World Social Forum to Address Human Genetic Technologies [Sitio en Internet] Disponible en http:/ /www.forumsocialmundial.org.br; CIOMS. Pautas éticas para la investigación biomédica en seres humanos. Geneva: CIOMS; 2002.

\section{¿Existen las condiciones para la discusión sobre genética en América Latina?}

El debate democrático ha tenido más bajas que altas en América Latina, y la discusión sobre las implicaciones bioéticas de la genética puede cuestionar las estructuras de las relaciones sociales y del poder político. Sin embargo, la globalización de la información y la sensibilización de los medios de comunicación han propiciado las condiciones para la participación pública. El quid está en la necesidad sentida de la prioridad de esta discusión frente a los problemas de ética social y de acceso a los servicios de salud, tan apremiantes en cada uno de los países latinoamericanos. El debate social está empañado por el desconocimiento, las posiciones sensacionalistas e irresponsables de los medios de comunicación, y por el fundamentalismo de las religiones cristianas. Todavía en las academias y sociedades médicas las instancias de discusión están frecuentemente sujetas a las presiones de los diferentes grupos de poder, y el integrismo religioso se hace presente. Por ello, las instancias actuales no pueden dictar normas definitivas, sino plantear ejes temáticos y consensos de mínimos que tengan en cuenta los aspectos particulares de la región latinoamericana.

Por otra parte, las “...condiciones genéticas médicas son conocidas por una confusión de sinónimos, acrónimos y epónimos que distorsionan la precisión histórica [...] No existe un comité para una nomenclatura internacional formal". Según un informe del Royal Devon and Exeter Hospital, lo que permite la existencia de 6.028 epónimos ligados a 2.451 científicos en la base de datos de Internet(6). Esta proliferación de nombres para representar una patología dificulta el intercambio de información entre médicos y países y agrega a la confusión del público. 


\section{Los derechos humanos en salud en América Latina}

Todas las Constituciones de América Latina reconocen el derecho a la salud de sus ciudadanas y ciudadanos. La implementación de estos derechos depende del marco legal de cada país y de la distribución de sus recursos económicos y sociales(7), por lo que se observan grandes desigualdades entre países y al interior de cada uno, ya sea en cobertura de seguro social y/o acceso a los servicios de salud. En cuanto a la genética, el derecho a consejería se ve empañado por la penalización del aborto en la mayoría de los países y por la falta de estructuras sociales de apoyo para las enfermedades genéticas discapacitantes.

Recientemente, los derechos de los enfermos han sido reconocidos oficialmente; su aplicación, sin embargo, está todavía fuertemente marcada por las relaciones culturales y sociales de dependencia y sumisión al poder médico. Estas relaciones verticales están acentuadas por la falta general de conocimientos en salud y la de conocimientos generales sobre biología humana, debido a lo cual las interrogantes de la genética serán resueltas según el sentimiento de responsabilidad moral y de respeto por los derechos humanos de los enfermos que tengan el médico en general y el genetista en particular. La participación de los pacientes dependerá de su acceso a la información a través de libros, revistas o Internet, lo que limita esta categoría a la clase media con escolaridad media o universitaria (20\% a 35\% de la población en América Latina, según la CEPAL 2000). Por lo tanto, la responsabilidad de los servicios de salud en entregar una información científica, clara y comprensible para la mayoría de las poblaciones es un elemento esencial de la capacidad de decisión de los usuarios y usuarias de estos servicios; en el campo de la genética, esta responsabilidad plantea un reto frente a la ignorancia y a los mitos y prejuicios existentes.

\section{El mito de la "salud"}

La velocidad de los cambios tecnológicos y sociales del mundo occidental actual ha traído consigo la pérdida del tejido social histórico; la construcción de nuevas relaciones, además, conlleva incertidumbres y miedos cuya característica es su difusión rápida y masiva a través de los medios de comunicación. La pobreza (40 a $60 \%$ de la población latinoamericana) aumenta la ignorancia y el miedo, y las personas buscan refugio en mitos y religiones que refuerzan su desconocimiento y las margina de los aportes de la ciencia.

En esta época de contradicciones, las muertes accidentales a cualquier edad son toleradas, ya que se ven como eventos no deseados pero independientes de la voluntad de las personas y sus familiares. Al contrario, las muertes "esperadas", por enfermedad crónica y por envejecimiento biológico, son rechazadas como desafíos al conocimiento científico y a las posibilidades que éste ofrece. Los medios de comunicación son la parte visible del mito de la salud a cambio de conductas especiales recomendadas por la medicina: dietas, prácticas deportivas, sexuales, crianza de los hijos y las hijas, entre otras prácticas.(8). Los avances científicos y tecnológicos refuerzan este mito, ya que cada vez más existen diferentes posibilidades para tener un cuerpo libre de enfermedades o completamente reparado. Las exigencias de la clase media latinoamericana de tener acceso a estas posibilidades descansan sobre este mito del poder de la medicina de ofrecer salud y juventud. Los términos "tercera edad" y "cuarta edad" responden a la concepción aséptica de lo "políticamente correcto", silenciando las enfermedades y las necesidades diferentes de la etapa de la vejez, y la muerte como desenlace ineludible. La juventud y la reproducción son los opuestos a la desaparición física y al olvido. En este contexto, la medicina y, particularmente, la genética, deben, su- 
puestamente, permitir una reproducción "saludable" según los deseos profundos de cada persona. En América Latina el avance de este fenómeno depende de la velocidad de introducción de la "nueva" cultura de lo inmediato presente y de la cohesión social y cultural en cada país. Las categorías más vulnerables son las que no tienen una cultura fuertemente enraizada en la sociedad en su conjunto.

Es bueno, entonces, recordar la función esencial de la medicina: reparación de los daños (traumas, quemaduras) y de las enfermedades (atención y rehabilitación), y sostén del proceso natural de la vida (prevención) para una calidad de vida aceptable. La genética no escapa a las obligaciones de estas funciones, aun si su rol específico en la prevención es, todavía, más accesible que para la atención y la rehabilitación. En ambos casos, estas funciones deben tomar en cuenta los principios de precaución (no maleficencia), de respeto a la integridad de las personas y de justicia (como equidad de acceso a los medios para disminuir o anular los efectos de las enfermedades genéticas).

\section{Los campos de la genética}

Desde la teoría de herencia cromosómica de Mendel, en 1865, la genética tiene dos campos primordiales de acción: la investigación y la clínica, los cuales están íntimamente ligados. La investigación se ocupa particularmente de la herencia cromosómica de las especies, de las mutaciones de los cromosomas y de la relación entre los diferentes cromosomas. Desde el descubrimiento del ADN en 1953, por Watson y Crick, la genética se ha desarrollado a una velocidad importante marcada por fechas, como el primer bebé probeta en 1981, la primera clonación de un ratón en 1990, y el Proyecto de Genoma Humano en 1997. En el año 2000 se desarrollaban 350 proyectos de aplicación de la clínica(9).
La fecundación extrauterina y el diagnóstico genético preimplantación, que permite el análisis del genoma de un embrión entre el momento de la fecundación in vitro y el de la implantación in útero ( $7^{\circ}$ día), así como el método de amplificación de ADN, han permitido aplicar los conocimientos genéticos a la clínica: diagnóstico de la mutación presente en uno de los padres, no ligada al sexo y responsable de una enfermedad monogenética, como la fibrosis quística; diagnóstico de las mutaciones responsables de ciertos cánceres. Pero las terapias genéticas de algunas enfermedades tienen todavía pocos resultados y son controversiales: al inicio de 1990, la terapia génica pareció abrir la esperanza de una mejoría de la calidad de vida y de su prolongación para las personas con enfermedades genéticamente determinadas (como los cánceres), ya que los científicos podían insertar genes saludables en los cromosomas de las personas enfermas ${ }^{2}$. Sin embargo, la muerte del joven Jesse Gelsinger en Estados Unidos- por participar en una investigación genética clínica, sacudió a la comunidad científica ${ }^{3}$; actualmente, las investigaciones son experimentales y bajo fuerte control.

Pero estos descubrimientos, fracasos y dificultades han enriquecido el debate filosófico sobre la búsqueda de la esencia del ser humano a pesar de la tiranía de la tecnología(3) y del uso autoritario del conocimiento científico. La comercialización de la tecnología médica, que

Gene therapy. [Sitio en Internet] Disponible en www.pbs.org/ saf/1202/features/genetherapy.htm; Human Genome Project. [Sitio en Internet] Disponible en www.ornl.gov/hgmis/ medicine/genetherapy.html; The Genetic Interest Group [Sitio en Internet] Disponible en www.gig.org.uk/; Gene Therapy Advisory Committee. [Sitio en Internet] Disponible en www.doh.gov.uk/genetics/gtac/index.htm; European Society of Gene Therapy. [Sitio en Internet] Disponible en www.esgt.org/

Jesse Gelsinger. [Sitio en Internet] Disponible en www.cancer-coverup.com/cancer-horror-stories/jessegelsinger-o2.html; www.humangenetherapy.com/french/ history/biotech.pdf 
preside el desarrollo de la ciencia en general y de la genética en particular en lugar de ponerse al servicio del ser humano, es materia recurrente en las críticas que abogan por una ciencia más humana.

\section{La consejería genética}

La dificultad o la imposibilidad de acceder a las pruebas genéticas en América Latina forma parte del problema general de acceso a los recursos de salud, más aún cuando no se consideran como una necesidad que amerite integrarlas a los paquetes básicos de salud propuestos por las reformas estructurales del sector público. Para el grupo social que sí puede acceder a las pruebas genéticas, ¿cómo se da la información sobre las enfermedades incurables y no prevenibles? ¿Y a qué da derecho esta información?

Las recomendaciones de la Organización Mundial de la Salud para la asesoría genética a pacientes y familiares (1997) son las siguientes(5):

1. "Información completa, cuidadosa, imparcial y neutral (excepto si existe un tratamiento accesible), en un lenguaje claro que los consultantes puedan entender. Esta información debe incluir todos los resultados, inclusive los resultados ambiguos y los que el(la) asesor(a) genético(a) no considere relevantes, sin informar los resultados sin relación con la salud, como la no paternidad o el sexo del feto". La realidad muestra que esta primera recomendación choca con los prejuicios y las creencias religiosas de los(las) médicos(as) que, frecuentemente, presentan la información que estiman necesaria para la toma de decisión de los padres y que corresponde a su propia visión.

2. "Aceptar las decisiones que tomen los(las) consultantes". En el sistema vertical de las relaciones clínicas que se da en la mayoría de nuestros países, reforzado por los prejuicios paternalistas, étnicos y de clases sociales, esta posición de respeto por la decisión de los consultantes es excepcional. Frecuentemente, el personal de salud trata de influenciar las decisiones hacia lo que considera lo mejor para el(la) consultante y su familia.

3. "Comunicar que el deber ético del médico es decir a los familiares que pueden tener un riesgo genético al mismo tiempo que debe respetar la decisión de las personas y de las familias de no conocer la información genética y los resultados de los estudios, excepto cuando se trate de pruebas para enfermedades tratables en recién nacidos y niños". La aparente contradicción entre el deber ético de información y el respeto por la decisión de no conocer de la familia puede crear un dilema importante para el(la) médico(a), si no tiene conocimientos sobre bioética que le preparen para entender las razones de algunas familias para rechazar la información; y esta formación es todavía incipiente en América Latina, como en muchos países del mundo. Las condiciones de trabajo en los servicios públicos amenazan a la confidencialidad y agravan el dilema médico. Por su parte, la familia enfrenta el problema de acceso a los recursos para tratar a su recién nacido.

4. "Preservar la integridad de la familia e informar sobre la importancia de revelar su estado de portador(a) al cónyuge o pareja, si es que desea procrear, y comentarles acerca de los posibles efectos dañinos de esa revelación sobre el matrimonio". A pesar de los avances en los derechos de las mujeres con la integración de los acuerdos de Beijing (1995), en las leyes de la mayoría de los países de América Latina el machismo sigue marcando las relaciones de pareja. En 
general, la mujer es receptora de la información porque el machismo disminuye la participación de los hombres en la salud. Al recibir las informaciones negativas, la mujer se encuentra sola para digerirlas y enfrentar sus sentimientos de angustia y de culpabilidad para, luego, transmitirlas al resto de la familia. Este sufrimiento psicológico se ve agravado por la ausencia de soluciones que no sean el aborto en países en los cuales éste es penalizado legal y moralmente; así es que la información genética, en el contexto de los países latinoamericanos, en lugar de ser una información liberadora que permita a la mujer y a la pareja decidir interrumpir un embarazo de un producto no viable o muy enfermo, aumenta las contradicciones de las mujeres con la sociedad actual.

Para los hombres, la aceptación de llevar, él mismo o su pareja, un potencial genético que puede transmitir una enfermedad o un defecto es difícilmente soportable, puesto que son reconocidos, socialmente, como procreadores. A menudo, hay ruptura de la pareja con abandono de la mujer y ruptura de su intimidad biológica al quedar, públicamente, como la culpable de la ausencia o del defecto de la descendencia, lo que crea una situación extremadamente delicada para las mujeres cuando se enteran de estas noticias. La posibilidad de fertilización extrauterina está reservada a las más preparadas cultural y económicamente. Este punto es uno de los más difíciles de resolver por parte de los médicos si no se apoyan en un equipo de salud con enfermeras, asistentes sociales, psicólogos y grupos de la comunidad. La última decisión del $\mathrm{CCNE}^{4}$, en Francia (Le Monde, 2 de octubre de 2003), considera que “...una persona informada de que es portadora de una ano-

Comité Consultatif National d'Ethique pour les sciences de la vie et de la santé. malía genética no debe ser sancionada por la ley si no transmite esta información a su familia. Igualmente, el médico no puede ser obligado a dar esta información a las personas que podrían beneficiarse de ella. La revelación de ser portador(a) de una mutación genética o de una anomalía cromosómica puede ser traumática, pero también culpabilizadora o humilladora". El CCNE considera que cualquier trasgresión del principio del secreto médico puede traer consigo un efecto negativo para el tamiz genético ya que “...las personas podrían sentirse amenazadas por una divulgación de elementos de su intimidad biológica..." y no puede haber equivalencia con la declaración obligatoria de las enfermedades infecciosas: "...el interés del grupo no puede ser defendido con sanciones penales para la persona o el médico." ${ }^{5}$ Esta posición, ¿puede ser viable en América Latina si tomamos en cuenta las consideraciones anteriores?

5. "Proteger la privacidad de los individuos y las familias de intrusiones injustificadas por parte de empleadores, aseguradoras y escuelas, e informar a las personas y a las familias acerca del posible mal uso de la información genética por parte de terceros". ¿Cómo hacer compatibles estas recomendaciones con las anteriores en el sistema de salud público o de seguro social, y frente a la necesidad de integrar una estructura social comunitaria y solidaria? Es un dilema que amerita un debate social profundo sobre un tipo de sociedad que respete los derechos humanos individuales al mismo tiempo que rescate los valores de solidaridad y cohesión de las sociedades campesinas indígenas. Algunas sociedades médicas de Japón consideran que los padres pueden en-

Le Comité d'éthique hostile à l'obligation d'informer la famille d'un risque génétique. Le Monde, 2.10.03. 
tregar, voluntariamente, a las escuelas la información genética de sus hijos(as) si necesitan algunos tratamientos o cuidados especiales para su patología(10). Por su parte, la Academia Americana de Pediatría recomienda que las pruebas genéticas para condiciones que se inicien en la edad adulta deben ser diferidas hasta que los(las) adolescentes desarrollen una madurez que les capacite para decidir sobre su cuerpo, y no apoya este tamiz en la niñez(11). Cada sociedad debe llegar a un consenso mínimo que respete los derechos de la niñez a la integridad de su persona $\mathrm{y}$, al mismo tiempo, le permita hacer uso de los recursos necesarios para lograr y mantener la calidad de vida que desea.

6. "Juzgar en qué momento el(la) consultante está listo(a) para recibir la información con el fin de evitar producir un daño grave psicológico o social". La ausencia de médico familiar en la mayoría de los países y los contactos escasos entre los proveedores y los usuarios de los servicios de salud dificultan este juicio y propician situaciones traumáticas.

\section{El diagnóstico prenatal}

El diagnóstico prenatal brinda informaciones sobre el estado de salud del feto para decidir continuar o interrumpir el embarazo si se detecta anormalidad fetal. La Organización Mundial de la Salud (1997) diseñó algunos lineamientos(5):

1. "Debe estar disponible para aquellos con mayor necesidad médica, sin importar la capacidad de pago u otras consideraciones, lo mismo que otros servicios de genética. Debe estar disponible independientemente de la opinión de la pareja respecto del aborto. En ocasiones resulta útil para que los padres preparen el recibimiento de un niño con al- guna anormalidad". Las restricciones de los presupuestos de salud en las políticas económicas actuales, el aumento de la pobreza, la penalización del aborto, las escasas estructuras de apoyo contradicen esta primera recomendación en la mayoría de nuestros países.

2. "Es voluntario..." [y] "Debe ser precedido y seguido por asesoramiento genético". Las interrogantes presentadas para el asesoramiento genético son válidas para estas dos recomendaciones, pero deben considerarse como una meta de excelencia de la atención médica en el campo de la genética.

3. "Debe realizarse sólo por razones relevantes para la salud del feto o la madre y no es aceptable para la selección de sexo, excepto en caso de enfermedades ligadas al cromosoma $\mathrm{X}$, ni para pruebas de paternidad, excepto en caso de violación o incesto". La realidad enseña que, aun en los embarazos sin complicaciones, las parejas quieren conocer el sexo del feto para preparar el recibimiento y que forma parte del ritual social alrededor del nacimiento; no se ha visto que este conocimiento implique un sesgo a favor o en contra de un sexo particular en América Latina, por lo que esta recomendación debe ser matizada y adaptada a cada caso. Por otra parte, la paternidad irresponsable imperante en varios países de Centroamérica ha llevado a los gobiernos a promover leyes que permitan a la madres inscribir a sus hijos(as) bajo su paternidad (Costa Rica, 1999, Panamá, 2001). Estas leyes responden a una necesidad social de respeto a los derechos de las mujeres y de la niñez, pero favorecen la negación de la responsabilidad autónoma de los participantes de esta relación sin educación previa de la pareja. 
4. "La decisión de la mujer o la pareja de abortar o continuar el embarazo de un feto afectado debe ser respetada y protegida en el marco de la familia, las leyes, la cultura y la estructura social del país. La pareja y no el profesional es la encargada de tomar la decisión". Esta formulación ambigua de la recomendación refleja las diferentes leyes de aborto en los países latinoamericanos y hace recaer sobre la pareja la entera responsabilidad de su decisión. Esta posición se ampara en el respeto de la autonomía de la pareja y de la neutralidad de los profesionales de la medicina; no obstante, las trabas burocráticas que imponen las leyes de aborto, las convicciones religiosas de muchos médicos en su contra, y el trauma psicológico de esta decisión para la pareja resultan, frecuentemente, en la continuación de un embarazo ya no deseado o en aborto séptico.

\section{Tamiz genético y pruebas genéticas}

El tamiz genético es una clase de pruebas que se realiza en personas aparentemente sanas, con el propósito de identificar el riesgo para desarrollar una enfermedad, como la fenilcetonuria, o un síndrome. Las recomendaciones de la Organización Mundial de la Salud (1997) son las siguientes(5):

1. "Son voluntarias. En los recién nacidos sólo son obligatorias si el tratamiento les beneficia.

2. Son precedidas por la información adecuada sobre sus propósitos, posibles resultados y probables opciones.

3. Se realizan después de notificárselo a la población, si constituyen estudios epidemiológicos anónimos".

Por el costo de estas pruebas y la falta de registros epidemiológicos sobre este tipo de enfermedades, el tamiz se emplea poco en la mayoría de nuestros países. Aun cuando el tamiz de enfermedades prevalentes, como la anemia falciforme, cuenta con el apoyo de los(las) pediatras, las variaciones de las políticas de salud, que designan los presupuestos, influyen negativamente sobre la sostenibilidad de estos programas (Panamá). Otro problema es la falta de estudios sobre la prevalencia de las enfermedades genéticas en cada uno de los países latinoamericanos y sobre su costo, por lo que el debate bioético no tiene los datos objetivos en este campo para proponer elementos para la justicia.

A su vez, los avances tecnológicos y su rápida comercialización presentan nuevos problemas, denunciados por la United Kingdom's Human Genetics Commission en un informe al gobierno inglés: "La genética moderna no debe ser mal usada comercialmente. La información del público es vital y una manera adecuada de ayudar a las personas a decidir cuáles pruebas genéticas son útiles para ellas es darles las armas de los hechos". El informe recomienda que las pruebas estén bajo reglamentación para asegurar su calidad y su conformidad a los propósitos que dicen perseguir; además, se debe desalentar su uso doméstico y, al contrario, desarrollar servicios de atención genética que permitan el acceso a cualquier prueba genética clínicamente relevante y útil(12).

La globalización de los conocimientos y modas, y la apertura de los mercados sin reglamentaciones locales dejan entrever nuevos problemas sobre los cuales las sociedades latinoamericanas y los comités de bioética deben reflexionar.

\section{La investigación en genética y el consentimiento informado}

La investigación en seres humanos debe realizarse sobre la base de una información com- 
pleta, veraz y clara que permita la participación libre, voluntaria y responsabilizada de las personas involucradas. La investigación en genética no difiere de la investigación en general. Sobre la base de las normas bioéticas de la investigación, la Organización Mundial de la Salud (1997) definió los puntos necesarios para un consentimiento verdaderamente informado, y en los cuales el último ítem es específico para la genética(5):

1. "Propósito y naturaleza del estudio.

2. Razones de la invitación a participar y constancia de que la colaboración es voluntaria.

3. Procedimientos programados.

4. Riesgos e incomodidades de las pruebas.

5. Confidencialidad de los datos de identificación del(de la) participante.

6. Nombre del(de la) investigador(a) para preguntas y aclaraciones.

7. Derecho a dejar el estudio en cualquier momento.

8. Derecho de la persona o de la familia a seguir recibiendo la atención médica aunque abandone el estudio.

9. Posibles beneficios para otras personas y para la ciencia.

10. Inseguridad de los resultados de las pruebas y asesoramiento genético."

La historia reciente ha dejado recuerdos amargos en la población indígena con investigaciones que no respetaron estos principios ${ }^{6}$. Pero la vigilancia de los grupos sociales orga-

Cecchetto S. Patentar Indios. Genética, dominación e identidad cultural en el sur argentino-chileno. [Sitio en Internet] Disponible en www.bioetica.org nizados y la formación de comités de ética de la investigación en las diferentes universidades y en el ámbito nacional deben corregir y mejorar las deficiencias existentes.

\section{Las manipulaciones de la genética}

Nos centraremos en los años recientes y en problemas que pueden reproducirse en América Latina. Así, la genética ha cuestionado la clasificación racial en medicina y en la investigación biomédica en Estados Unidos(13). Esta preocupación responde al hecho histórico de discriminación racial, aunque los epidemiólogos y otros científicos estadounidenses consideran que esta clasificación es útil para emitir hipótesis sobre los factores de riesgo genético y ambiental, porque hace hincapié sobre la región geográfica del origen ancestral de un grupo particular y que, históricamente, las particularidades genéticas han sido determinadas por la geografía(14). Los adversarios de la clasificación racial no niegan las diferencias y particularidades entre un grupo y otro, pero consideran que los factores socioeconómicos tienen más importancia para la incidencia y el pronóstico de las enfermedades genéticas, como la diabetes mellitus tipo 2(15). Para América Latina, donde el racismo está subyacente en todos los países -a pesar del mestizaje-, esta clasificación trae consigo más peligros que beneficios.

El otro peligro para la genética es la concepción neoliberal de que todo producto tiene un valor comercial. Estos conceptos no son particulares de la genética, pero, en este caso, se trata del cuerpo humano o de sus partes: la existencia de venta y tráfico de órganos para transplantes debe poner en alerta sobre las consecuencias de estas ideas. La solicitud de patentes sobre el patrimonio genómico o sobre secuencias de ADN (Venter y el National Institute of Health, 1991; Directiva del Conce- 
jo de Ministros de la Unión Europea, 1998) ha encontrado la resistencia de los grupos organizados de la sociedad civil (coalición de ochenta religiones diferentes, 1995; coalición de feministas de setenta países, 1996), que llevó a la Declaración Universal sobre el Genoma Humano y los Derechos Humanos, de la UNESCO en 1997(16) y a la declaración de condena de patentes de genes por los dirigentes del G8, más Brasil, China, México y la India, en 2000. Sin embargo, la Comisión Europea ha emitido una ley que permite patentar las invenciones biotecnológicas desde el 30 de julio de $2000^{7}$. Esta ley excluye: las patentes sobre las secuencias de DNA sin función claramente identificada, la clonación humana o la modificación de la identidad genética, el uso de embriones humanos para propósitos industriales y los procesos para modificar la identidad genética de los animales sin beneficios médicos sustanciales. Pero su propia existencia permite considerar que el patrimonio genético depende de las leyes del mercado y no de la bioética y de los principios de salud contenidos en los Derechos Humanos ${ }^{8}$.

\section{¿Quién tiene derecho sobre las células madres?}

Las células madres son células "adultas" (ES) cultivadas in vitro o derivan de células germinales de fetos abortados a la $8^{\mathrm{a}}$ semana (EG). En ambos casos fueron donadas por una persona o pareja, con consentimiento, para la investigación presentada por el(la) médico(a) a cargo; a su vez este médico considera que

European Commission. [Sitio en Internet] Disponible en http://europa.eu.int/comm/index_en.htm; EuropaBio, the European Association for Bioindustries. [Sitio en Internet] Disponible en http://www.europabio.org/pages/index.asp; European commission: Biotechnological inventions. [Sitio en Internet] Disponible en http://europa.eu.int/comm/ internal market/en/indrop/invent/ind ex.htm.

US Patent and Trademark Office. [Sitio en Internet] Disponible en http://www.uspto.gov/; Nuffield Council on Bioethics. [Sitio en Internet] Disponible en http:// www.nuffieldbioethics.org/home/ representa el derecho de la genética a buscar respuestas para la generación actual y futura; pero los grupos que financian la investigación reclaman el derecho de propiedad según las leyes del derecho comercial. La validez de los argumentos de cada uno refleja la complejidad del problema en la sociedad actual; hay una multiplicidad de actores y contradicción entre el fundamentalismo neoliberal y los Derechos Humanos, lo que resulta en la ausencia de consenso y de legislación sobre el particular. La situación no es nueva, ya que se ha dado con los transplantes de órganos, pero ella es ejemplar porque refleja todas las ambigüedades, prejuicios y contradicciones de la sociedad con la genética. ¿Cómo resolverlas en sociedades con desigualdades tan grandes que impiden el diálogo democrático? ¿Qué pasa cuando los Estados pierden autonomía y autoridad moral que les permita fungir como árbitros? A estas preguntas se suman otras: ¿Qué tipo de células madres utilizar? ¿Qué permite la legislación nacional? Todas estas interrogantes abren el debate sobre el embrión como persona, la autonomía, la integridad, la no maleficencia, la justicia y los derechos humanos, en una cadena que refleja la utopía de una sociedad justa y ética.

\section{Conclusión}

La genética, por su novedad y la íntima relación entre las incertidumbres de la investigación y la clínica, plantea múltiples interrogantes que sólo podrán ser resueltas con los avances del conocimiento, acompañados por el debate democrático sobre el tipo de sociedad a la cual aspiramos para nosotros y las generaciones futuras. 


\section{Referencias}

1. Farmer P. Pathologies of power: rethinking health and human rights. American Journal of Public Health 1999; 89 (10): 1486-96.

2. Frosini V. Derechos Humanos y Bioética. Bogotá: Editorial Temis S. A.;1997: 88-90.

3. Sommer SE. Genetics, Cloning and Bioethics: How Does Science affect our Lives. Buenos Aires: Editorial Biblios; 1999.

4. Beauchamp T, Childress J. Principles of Biomedical Ethics. New York: Oxford University Press; 1989.

5. Gracia D. La confidencialidad de los datos genéticos. En: Gracia D. Ética de los Confines de la Vida. Bogotá: Editorial El Búho; 1998.

6. Dobson R. New method for naming genetic diseases is proposed. British Medical Journal 2003; 326: 416.

7. Casas JA. Los retos de la bioética en América Latina: equidad, salud y derechos humanos. En: Lolas F. Bioética y Cuidado de la Salud. Equidad, calidad, derechos. Santiago de Chile: Programa Regional de Bioética OPS-OMS; 2000:19-34.

8. Souccar T. Les cliniques du rêve pour allonger la vie. Sciences et Avenir 2000; Déc: 56-61.

9. Savoirs/Dossier. Nos gènes mis à nu. La Recherche 2000; 332: 26-59.

10. Takako Takano How to share or keep privacy of genetic information: implication for school health services. British Medical Journal 2003; 326: 781a.

11. American Academy of Paediatrics. Ethical issues with genetic testing in Paediatrics (RE9924). Paediatrics 2001; 107: 1451-5.

12. Eaton L. (News) Commission warns against selling genetic tests direct to the public. British Medical Journal 2003 Apr. 12;326(7393): 781.

13. Angier N. Do races differ? Not really, genes show. New York Times 2000 August 22; FI.

14. González Buchard E, et al. The Importance of Race and Ethnic Background in Biomedical Research and Clinical Practice Bristish Medical Journal 2003, 348: 1170-5.

15. Schulman KA, Berlin JA, Harless W, et al. The effect of race and sex on physicians' recommendations for cardiac catheterisation. The New England Journal of Medicine 1999;340: 618-26.

16. UNESCO. Declaración Universal sobre el Genoma Humano y los Derechos Humanos. UNESCO, 3 de diciembre de 1997. 